\title{
Design of mooring system
}

\author{
Zheng Hu \\ No. 689, Huadian Road, Beishi District, Baoding City, Hebei Province, China \\ 1415037523@qq.com \\ Zheng $\mathrm{Hu}$
}

Keywords: Holistic Methods, Catenary method, Fluid distribution, Mooring system

Abstract. The main research of this paper is that the optimal scheme for the design of a mooring system in a different state is to balance the whole system. In order to accurately describe the relevant position, length, shape and tilt Angle of the object, this article is based on the minimalist principles, in order to anchor point position as the origin, the direction of the sea level for the $\mathrm{x}$ axis is parallel, perpendicular to the direction for the $\mathrm{y}$ axis is, sea level at anchor in the plane rectangular coordinate system is established.

In order to solve the problem, first, the overall force of the system is analyzed, and for the sake of simplicity, all the links of the anchor chain are separated from the bottom of the sea. The external force by the system for the whole system, is under the condition of static water only from wind, support and resistance of the bottom, all the objects in the sea of gravity and buoyancy and buoy gravity and buoyancy. According to the principle of force equilibrium, to orthogonal decomposition of the force, it is concluded that in equilibrium the $\mathrm{x}$, $\mathrm{y}$ direction of the force, further analysis for the whole system by the wind and the sea of equal resistance. Due to buoy the stressed area of wind and buoyancy drainage volume and water depth, so the anchor force analysis, get two groups about draft depth equation, and then work out when the wind speed of $12 \mathrm{~m} / \mathrm{s}$, draft a depth of 0.8661 meters, wind and buoyancy is respectively $204 \mathrm{~N}$ and $27891 \mathrm{~N}$; When the wind speed was $24 \mathrm{~m} / \mathrm{s}$, the depth of the draft was 0.8347 meters, and the wind and buoyancy were $839 \mathrm{~N}$ and $26880 \mathrm{~N}$ respectively. Then the curve equation of the anchor chain shape was determined by the suspension chain method [1]

Buoy floating range is 16 meters radius of circular surface, steel drum and vertical direction Angle is $3.01^{\circ}$, at last, according to the result of solving the chain when wind speed of $12 \mathrm{~m} / \mathrm{s}$ was not fully prove the hypothesis of raised.

\section{Introduction}

The transmission node of the near shallow sea observatory is composed of buoyage system, mooring system and acoustic communication system. The buoy system of a certain type of transmission node can be simplified to the cylinder with a diameter of $2 \mathrm{~m}$ and $2 \mathrm{~m}$, and the mass of the buoy is $1000 \mathrm{~kg}$. Mooring system consists of steel pipe, steel barrel, weight ball, electric welded anchor chain and special anti-dragging anchor. The quality of the anchor is $600 \mathrm{~kg}$, and the anchor 
chain is chosen for the plain link. The steel pipe has four sections, each length $1 \mathrm{~m}$, and the diameter is $50 \mathrm{~mm}$, each section has a mass of $10 \mathrm{~kg}$. The tangent line of the anchor and the anchor is required to be no more than 16 degrees from the Angle of the seabed. The water acoustic communication system is installed in a sealed cylindrical steel barrel with a length of $1 \mathrm{~m}$ and $30 \mathrm{~cm}$ outside, and the total quality of the equipment and steel drums is $100 \mathrm{~kg}$. The steel drum shall be connected with the fourth steel pipe and the welded anchor chain. When the steel drum is vertical, the sound communication equipment works best. The working effect of the equipment is poor when the tilting Angle of steel barrel is more than 5 degrees. In order to control the Angle of the steel barrel, the steel drum and the welded anchor link can suspend the heavy ball. Mooring system design problem is to determine the quality of the chain type, length and weight of the ball, make the draught of buoy and swimming area and Angle steel drum as small as possible.

The quality of the weight ball is $1200 \mathrm{~kg}$. Is the type of transport nodes cloth on $18 \mathrm{~m}$ water depth, sea level, sea water density of $1.025 \times 103 \mathrm{~kg} / \mathrm{m} 3$. If the water still, calculate the surface wind speed of $12 \mathrm{~m}$ and $24 \mathrm{~m} / \mathrm{s} / \mathrm{s}$ steel drum and each section of the steel tube Angle, shape, buoy mooring chain draught and swimming area.

\section{Analysis}

This paper in the mooring system under the condition of still water, with anchor as the origin of coordinates, to anchor for xoy plane, the plane in horizontal direction for $\mathrm{x}$ axis, in vertical direction for the y axis, vertical in xoy flat face as the y axis, build plane rectangular coordinate system S. Secondly, using the method of overall draft depth, in order to find out the draft of a buoy depth, the support of anchor is first, then force equilibrium analysis was carried out on the chain. Moreover, for steel tube Angle, using integral method to draw the first root steel pipe and force of the buoy connection point, and then according to the first root tube Angle to satisfy equation, calculate the Angle steel drum.

\section{Solution}

In order to accurately describe the cable equation and steel drum, deflection Angle steel tube, and quantitative description of the related physical quantity at first, this paper under the condition of the mooring system of still water, with anchor as the origin of coordinates, to anchor for xoy plane, the plane in horizontal direction for $\mathrm{x}$ axis, in vertical direction for the $\mathrm{y}$ axis, establish the following image plane rectangular coordinate system $\mathrm{S}$.

When all the $\mathrm{x}$ and $\mathrm{y}$ forces are zero, the equation of equilibrium is obtained by Newtonian mechanics:

$$
\left\{\begin{array}{c}
F_{f}=F_{w} \\
F_{b}+F_{N}=\sum_{i=1}^{7} m_{i} g
\end{array}\right.
$$

According to their known conditions, the relationship between wind and wind speed is as follows: 


$$
\begin{gathered}
F_{w}=0.625 \times S v^{2} \\
\mathrm{~S}=\mathrm{d}(\mathrm{H}-\mathrm{h}) \\
F_{b}=\rho_{\text {水 }} g s h
\end{gathered}
$$

All of the $\mathrm{x}$ and $\mathrm{y}$ forces are zero, and according to Newtonian mechanics, the equation of force balance of the anchor is:

$$
\left\{\begin{array}{c}
F_{N}=m_{7} g-T_{0} \sin \alpha \\
F_{f}=T_{0} \cos \alpha
\end{array}\right.
$$

According to the formula (1) (5) the tension $T_{0}$ and the supporting force $F_{N}$ of the anchor point

$$
\begin{gathered}
T_{0}=\frac{F_{w}}{\cos \alpha} \\
F_{N}=m_{7} g-F_{w} \tan \alpha
\end{gathered}
$$

Again, the formula (1) has the buoyancy $F_{b}$ :

$$
F_{b}=\sum_{i=1}^{7} m_{i} g-F_{N}
$$

According formula (2) (3) (7) (8) : when the wind speed is $24 \mathrm{~m} / \mathrm{s}$, the depth of the draft is 0.835 meters, $F_{b}=26877 \mathrm{~N}, F_{w}=839.04 \mathrm{~N}$ and $F_{f}=839.04 \mathrm{~N}$. When the wind speed is $12 \mathrm{~m} / \mathrm{s}$, the depth of the draft is $0.8661 \mathrm{~m}, F_{b}=27891 \mathrm{~N}, F_{w}=204.10 \mathrm{~N}$ and $F_{f}=204.10 \mathrm{~N}$.

\subsection{To solve the angle of inclination}

The equation of force balance for this point is:

$$
\left\{\begin{array}{c}
F_{1} \sin \theta_{1}=F_{w} \\
F_{1} \cos \theta_{1}+m_{2} g+m_{1} g=F_{b}
\end{array}\right.
$$

Therefore, the tilt Angle of the first tube is satisfied:

$$
\begin{aligned}
\tan \theta_{1} & =\frac{F_{w}}{F_{b}-m_{1} g-m_{2} g} \\
\tan \theta_{i} & =\frac{F_{w}}{F_{b}-m_{1} g-i \times m g}
\end{aligned}
$$

According to the above, the tilting Angle of the steel pipe is shown in table 1 and table 2: 
Table 1:The inclination of the steel pipe when the wind speed is $12 \mathrm{~m} / \mathrm{s}$

\begin{tabular}{cc}
\hline Steel pipe & The Angle between the tube and the vertical direction/degree \\
\hline The first steel pipe & 0.657 \\
The second steel pipe & 0.661 \\
The third steel pipe & 0.665 \\
The forth steel pipe & 0.669 \\
\hline
\end{tabular}

Table 2:The inclination of the steel pipe when the wind speed is $24 \mathrm{~m} / \mathrm{s}$

\begin{tabular}{lc}
\hline Steel pipe & The Angle between the tube and the vertical direction/degree \\
\hline The first steel pipe & 2.863 \\
2.880 \\
The second steel pipe & 2.895 \\
The third steel pipe & 2.915 \\
The forth steel pipe & \\
\hline & $\tan \theta=\frac{F_{W}}{F_{b}-m_{1} g-4 m_{2} g-m_{6} g}$
\end{tabular}

Type can be calculated by: when the wind speed of 12 meters per second, Angle is $0.709^{\circ}$ steel drum; When the wind speed is 24 meters per second, steel drum Angle is $3.103^{\circ}$.

\section{Reference}

[1] liu shu-sheng, wang yong. The application of the equation in the related calculation of FPSO anchor system [J]. China shipbuilding, 2011, 52 (z1) : 116-122.

[2] DeleteEdit chun-ling hao, zhang also fly, a poet, and so on. The velocity distribution and its own chain stiffness impact on the elastic deformation and stress of single chain system [J]. Journal of oceanographic research, 2006, 24 (3) : 91-95.

[3] DeleteEdit Chen guang ren zhiliang sun haizhu. The least square curve fitting and matlab implementation [J]. Automaticity, 2005, 24 (3). 